\title{
Mixed Convection Boundary Layer Flow over a Permeable Vertical Flat Plate Embedded in an Anisotropic Porous Medium
}

\author{
Norfifah Bachok, ${ }^{1}$ Anuar Ishak, ${ }^{2}$ and Ioan Pop ${ }^{3}$ \\ ${ }^{1}$ Department of Mathematics, Faculty of Science, Universiti Putra Malaysia, 43400 UPM Serdang, \\ Selangor, Malaysia \\ ${ }^{2}$ School of Mathematical Sciences, Universiti Kebangsaan Malaysia, 43600 UKM Bangi, Selangor, Malaysia \\ ${ }^{3}$ Faculty of Mathematics, University of Cluj, CP 253, 3400 Cluj, Romania
}

Correspondence should be addressed to Norfifah Bachok, norfifah@fsas.upm.edu.my

Received 12 November 2009; Revised 19 April 2010; Accepted 17 May 2010

Academic Editor: Mehrdad Massoudi

Copyright (c) 2010 Norfifah Bachok et al. This is an open access article distributed under the Creative Commons Attribution License, which permits unrestricted use, distribution, and reproduction in any medium, provided the original work is properly cited.

\begin{abstract}
An analysis is performed to study the heat transfer characteristics of steady mixed convection flow over a permeable vertical flat plate embedded in an anisotropic fluid-saturated porous medium. The effects of uniform suction and injection on the flow field and heat transfer characteristics are numerically studied by employing an implicit finite difference Keller-box method. It is found that dual solutions exist for both assisting and opposing flows. The results indicate that suction delays the boundary layer separation, while injection accelerates it.
\end{abstract}

\section{Introduction}

Transport processes through porous media play important roles in diverse applications, such as in geothermal operations, petroleum industries, and many others. Excellent reviews on this topic can be found in the books by Ingham and Pop [1], Vafai [2], Nield and Bejan [3], Vadasz [4], and in the review paper by Magyari et al. [5]. The study of convective heat transfer and fluid flow in porous media has received great attention in recent years. Most of the earlier studies (Minkowycz and Cheng [6], Cheng and Minkowycz [7], and Badr and Pop [8]) were based on Darcy's law which states that the volume-averaged velocity is proportion to the pressure gradient. Kaviany [9] used the line integral method to study the heat transfer from a semi-infinite flat plate embedded in a fluid-saturated porous medium. Jang and Shiang [10] studied the mixed convection along a vertical adiabatic surface embedded in a porous medium. Few studies of convective boundary-layer flows in porous media using 


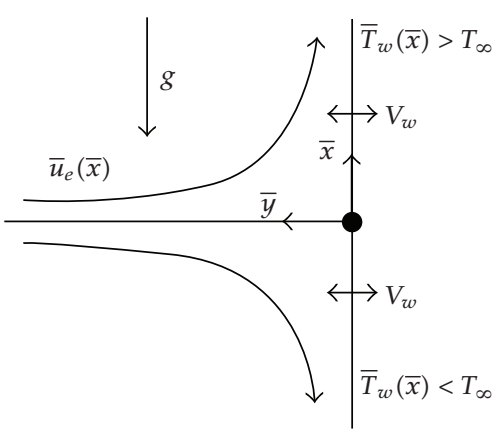

(a)

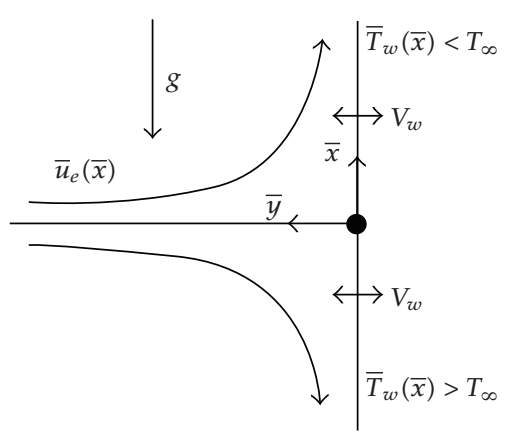

(b)

Figure 1: Physical model and coordinate system.

the Darcy-Brinkman equation model are considered for the momentum equation, for example, Hsu and Cheng [11], Rees and Vafai [12], Nazar et al. [13, 14], Ishak et al. [15], and Harris et al. [16].

All of the works mentioned above are conducted to flows over an impermeable surface embedded in a Darcian porous medium. The free convections with injection or suction over permeable vertical and horizontal plates in a porous medium were studied by Cheng [17], Merkin [18] and Minkowycz et al. [19]. Lai and Kulacki [20, 21] investigated the effects of injection and suction on mixed convection over horizontal and inclined surfaces embedded in fluid-saturated porous media. Elbashbeshy and Bazid [22, 23] analyzed the heat transfer over a continuously moving plate and mixed convection along a vertical plate embedded in a non-Darcian porous medium. Further, Elbashbeshy [24, 25] investigated the effects of suction and injection on mixed convection boundary layer flow over horizontal flat plate and mixed convection boundary layer flow along a vertical plate embedded in a non-Darcian porous medium.

The aim of this paper is to study the effects of suction and injection on the mixed convection boundary layer flow over a permeable vertical plate embedded in an anisotropic porous medium. Injection or withdrawal of fluid through a porous bounding heated or cooled wall is of general interest in practical problems involving film cooling, control of boundary layers, and so forth. This can lead to enhance heating (or cooling) of the system and can help to delay the transition from laminar flow (see Chaudhary and Merkin [26]). We mention to this end that such a study has also been done by Massoudi [27], Weidman et al. [28, 29], and Ishak et al. [30] for the classical problems of the boundary layers over a permeable wedge, moving flat plates, and permeable vertical flat plates. To the best of our knowledge, this problem has not been studied before and the results are new and original.

\section{Problem Formulation}

Consider the steady mixed convection boundary layer flow over a semi-infinite vertical permeable surface with a uniform surface temperature $\bar{T}_{w}(\bar{x})$ embedded in an anisotropic fluid-saturated porous medium, as shown in Figure 1. The uniform temperature of the ambient fluid is $T_{\infty}$, where $\bar{T}_{w}(\bar{x})>T_{\infty}$ for a heated plate and $\bar{T}_{w}(\bar{x})<T_{\infty}$ for a cooled plate. The corresponding velocity components in the $\bar{x}$ and $\bar{y}$ directions are $\bar{u}$ and $\bar{v}$, respectively, 
and the surface mass flux $\bar{V}_{w}$ is assumed to be constant with $\bar{V}_{w}>0$ for injection and $\bar{V}_{w}<0$ for suction. The permeabilities along the two principal axes of the porous matrix are denoted by $K_{1}$ and $K_{2}$. The anisotropy of the porous medium is characterized by the anisotropy ratio $K^{*}=K_{1} / K_{2}$ and the orientation angle $\phi$, defined as the angle between the horizontal direction and the principal axis with permeability $K_{2}$. Under the Boussinesq approximation, the basic equations of continuity, the generalized Brinkman-extended Darcy's law, and energy are given by (see Vasseur and Degan [31] or Bera and Khalili [32])

$$
\begin{gathered}
\frac{\partial \bar{u}}{\partial \bar{x}}+\frac{\partial \bar{v}}{\partial \bar{y}}=0, \\
a \bar{u}-b \bar{v}=\frac{\tilde{\mu}}{\mu} K_{1} \bar{\nabla}^{2} \bar{u}-\frac{K_{1}}{\mu} \frac{\partial \bar{p}}{\partial \bar{x}}+\frac{g \beta K_{1}}{v}\left(\bar{T}-T_{\infty}\right), \\
c \bar{v}=\frac{\tilde{\mu}}{\mu} K_{1} \bar{\nabla}^{2} \bar{v}-\frac{K_{1}}{\mu} \frac{\partial \bar{p}}{\partial \bar{y}} \\
\bar{u} \frac{\partial \bar{T}}{\partial \bar{x}}+\bar{v} \frac{\partial \bar{T}}{\partial \bar{y}}=\alpha_{m} \bar{\nabla}^{2} \bar{T}
\end{gathered}
$$

subject to the boundary conditions

$$
\begin{gathered}
\bar{v}=\bar{V}_{w}, \quad \bar{u}=0, \quad \bar{T}=\bar{T}_{w}(\bar{x}) \quad \text { at } \bar{y}=0, \\
\bar{u} \longrightarrow \bar{u}_{e}(\bar{x}), \quad \bar{T} \longrightarrow T_{\infty} \quad \text { as } \quad \bar{y} \longrightarrow \infty,
\end{gathered}
$$

where

$$
\begin{gathered}
a=\cos ^{2} \phi+K^{*} \sin ^{2} \phi, \quad b=2\left(K^{*}-1\right) \sin \phi \cos \phi, \\
c=\sin ^{2} \phi+K^{*} \cos ^{2} \phi .
\end{gathered}
$$

Here $\bar{u}_{e}(\bar{x})$ is the free stream velocity, $\bar{p}$ is the fluid pressure, $g$ is the acceleration due to gravity, $\alpha_{m}$ is the effective thermal diffusivity, $\beta$ is the coefficient of volumetric thermal expansion, $\tilde{\mu}$ is the effective dynamic viscosity, $\mu$ is the dynamic viscosity, and $v$ is the kinematic viscosity.

We now introduce the following nondimensional boundary-layer variables:

$$
\begin{gathered}
x=\frac{\bar{x}}{L}, \quad y=\operatorname{Pe}^{1 / 2} \frac{\bar{y}}{L}, \quad u=\frac{\bar{u}}{U_{\infty}}, \quad v=\operatorname{Pe}^{1 / 2} \frac{\bar{v}}{U_{\infty}}, \\
T=\frac{\bar{T}-T_{\infty}}{\Delta \bar{T}}, \quad u_{e}(x)=\frac{\bar{u}_{e}(\bar{x})}{U_{\infty}}, \quad V_{w}=\operatorname{Pe}^{1 / 2} \frac{\bar{V}_{w}}{U_{\infty}}
\end{gathered}
$$

where $U_{\infty}$ is the characteristic velocity, $L$ is the characteristic length, $\Delta \bar{T}$ is the characteristic temperature difference, and $\mathrm{Pe}=U_{\infty} L / \alpha_{m}$ is the Péclet number. Substituting the nondimensional variables (2.6) into (2.1)-(2.3), eliminating the pressure gradients from (2.2), 
and imposing the usual boundary layer approximations, we obtain the following boundarylayer equations for the present problem:

$$
\begin{gathered}
\frac{\partial u}{\partial x}+\frac{\partial v}{\partial y}=0 \\
a \frac{\partial u}{\partial y}=\varepsilon \operatorname{Da} \frac{\partial^{3} u}{\partial y^{3}}+\lambda \frac{\partial T}{\partial y} \\
u \frac{\partial T}{\partial x}+v \frac{\partial T}{\partial y}=\frac{\partial^{2} T}{\partial y^{2}}
\end{gathered}
$$

with the boundary conditions (2.4) which become

$$
\begin{gathered}
v=V_{w}, \quad u=0, \quad T=T_{w}(x) \text { at } y=0, \\
u \longrightarrow u_{e}(x), \quad T \longrightarrow 0 \quad \text { as } y \longrightarrow \infty,
\end{gathered}
$$

where $T_{w}(x)=\left(\bar{T}(\bar{x})-T_{\infty}\right) / \Delta \bar{T}$. Here Da is the Darcy-Brinkman parameter, $\lambda$ is the mixed convection parameter, and $\varepsilon$ is the modified Péclet number, which are defined as

$$
\mathrm{Da}=\frac{K_{1}}{L^{2}}, \quad \lambda=\frac{\mathrm{Ra}}{\mathrm{Pe}}, \quad \varepsilon=\frac{\tilde{\mu}}{\mu} \mathrm{Pe},
$$

where $\mathrm{Ra}=g K_{1} \beta \Delta \bar{T} L / v \alpha_{m}$ is the Rayleigh number for the anisotropic porous medium. It should be noted that $\lambda>0$ is for the assisting flow, $\lambda<0$ is for the opposing flow, and $\lambda=0$ corresponds to forced convection flow.

Integrating (2.8) with the boundary conditions $(2.10 \mathrm{~b})$ and introducing the stream function $\psi$, which is defined as $u=\partial \psi / \partial y$ and $v=-\partial \psi / \partial x$, we obtain

$$
\begin{gathered}
a\left(\frac{\partial \psi}{\partial y}-u_{e}(x)\right)=\varepsilon \operatorname{Da} \frac{\partial^{3} \psi}{\partial y^{3}}+\lambda T \\
\frac{\partial \psi}{\partial y} \frac{\partial T}{\partial x}-\frac{\partial \psi}{\partial x} \frac{\partial T}{\partial y}=\frac{\partial^{2} T}{\partial y^{2}}
\end{gathered}
$$

with the boundary conditions (2.10a) and (2.10b) which become

$$
\begin{gathered}
-\frac{\partial \psi}{\partial x}=V_{w}, \quad \frac{\partial \psi}{\partial y}=0, \quad T=T_{w}(x) \quad \text { at } y=0, \\
\frac{\partial \psi}{\partial y} \longrightarrow u_{e}(x), \quad T \longrightarrow 0 \quad \text { as } \quad y \longrightarrow \infty .
\end{gathered}
$$


The physical quantities of interest are the skin friction coefficient $C_{f}$ and the Nusselt number $\mathrm{Nu}$, which are defined as

$$
C_{f}=\frac{\tau_{w}}{\rho u_{e}^{2}}, \quad \mathrm{Nu}=\frac{L q_{w}}{k \Delta \bar{T}}
$$

where $\tau_{w}$ is the wall shear stress and $q_{w}$ is the wall heat flux, which are given by

$$
\tau_{w}=\mu\left(\frac{\partial \bar{u}}{\partial \bar{y}}\right)_{\bar{y}=0}, \quad q_{w}=-k\left(\frac{\partial \bar{T}}{\partial \bar{y}}\right)_{\bar{y}=0} .
$$

Substituting variables (2.6) into (2.15), and using (2.14), we obtain

$$
\left(\frac{\mathrm{Pe}^{1 / 2}}{\operatorname{Pr}}\right) C_{f}=\left(\frac{\partial^{2} \psi}{\partial y^{2}}\right)_{y=0}, \quad\left(P e^{-1 / 2}\right) \mathrm{Nu}=-\left(\frac{\partial T}{\partial y}\right)_{y=0},
$$

where $\operatorname{Pr}=v / \alpha_{m}$ is the Prandtl number for an anisotropic porous medium.

We consider now the case when the free stream velocity $u_{e}(x)$ and the surface temperature $T_{w}(x)$ vary linearly with $x$, namely,

$$
u_{e}(x)=x, \quad T_{w}(x)=x,
$$

and we look for a similarity solution of (2.12) of the form

$$
\psi(x, y)=x f(y), \quad T(x, y)=x \theta(y)
$$

It should be noted that this similarity solution corresponds to the mixed convection flow in a porous medium near the stagnation point on a vertical surface with a linear variation in the wall temperature. The corresponding situation for using the Darcy-Brinkman formulation of the governing equations and the slip condition on the surface was studied by Harris et al. [16]. Substituting (2.18) into (2.12), we obtain the following system of ordinary differential equations:

$$
\begin{gathered}
f^{\prime \prime \prime}+A\left(1-f^{\prime}\right)+\Lambda \theta=0, \\
\theta^{\prime \prime}+f \theta^{\prime}-f^{\prime} \theta=0,
\end{gathered}
$$


where $A=a /(\varepsilon \mathrm{Da})$ is the anisotropy parameter and $\Lambda=\lambda /(\varepsilon \mathrm{Da})$ is the modified mixed convection parameter with $\varepsilon \mathrm{Da} \neq 0$, and primes denote differentiation with respect to $y$. The transformed boundary conditions are

$$
\begin{gathered}
f(0)=f_{0}, \quad f^{\prime}(0)=0, \quad \theta(0)=1, \\
f^{\prime}(y) \longrightarrow 1, \quad \theta(y) \longrightarrow 0 \quad \text { as } \quad y \longrightarrow \infty
\end{gathered}
$$

where $f_{0}=-V_{w}$ is the suction or injection parameter with $f_{0}>0$ for suction and $f_{0}<0$ is for injection. When $\varepsilon \mathrm{Da}=0$ (inertial effect is neglected), (2.19) can be reduced to

$$
1-f^{\prime}+\lambda^{*} \theta=0
$$

where $\lambda^{*}=\lambda / a$, which is identical to that derived by Merkin [33] and subjected to the associated boundary conditions (2.21) with $f_{0}=0$ in his paper. Thus, this case will not be considered here.

Expressions (2.16) for the skin friction coefficient $C_{f}$ and the Nusselt number $\mathrm{Nu}$ become

$$
\left(\frac{\mathrm{Pe}^{1 / 2}}{\mathrm{Pr}}\right) C_{f}=x f^{\prime \prime}(0), \quad\left(\mathrm{Pe}^{-1 / 2}\right) \mathrm{Nu}=-x \theta^{\prime}(0)
$$

\section{Results and Discussion}

Equations (2.19) and (2.20) subject to the boundary conditions (2.21) have been solved numerically for some values of the governing parameters $f_{0}$ and $\Lambda$ using a very efficient finite-difference scheme known as the Keller-box method, which is described in the book by Cebeci and Bradshaw [34], and in the review paper by Keller [35]. This method has been successfully used by the present authors to study various boundary value problems (cf. [3641]).

The variations of the skin friction coefficient $f^{\prime \prime}(0)$ with $\Lambda$ together with their velocity profiles are shown in Figures $2-4$ for $A=1, f_{0}=0.2$, and $f_{0}=-0.2$, respectively, while the respective Nusselt number $-\theta^{\prime}(0)$ together with their temperature profiles is shown in Figures 5-7, to support the validity of the numerical results obtained. It is worth mentioning that all the velocity and temperature profiles satisfy the far field boundary conditions (2.21) asymptotically. In these figures the solid lines and the dash lines are for the first solution and second solution, respectively. The results for the skin friction coefficient $f^{\prime \prime}(0)$ and the Nusselt number $-\theta^{\prime}(0)$ as a function of $\Lambda$ show that it is possible to get dual solutions of the similarity equations (2.19) and (2.20) subject to the boundary conditions (2.21) for the assisting flow $(\Lambda>0)$ as well, beside that usually reported in the literature for the opposing flow $(\Lambda<0)$. Also for $\Lambda>0$, there is a favorable pressure gradient due to the buoyancy effects, which results in the flow being accelerated in a larger skin friction coefficient than in the nonbuoyant case $(\Lambda=0)$. For negative values of $\Lambda$, dual solutions $\left(\Lambda_{c}<\Lambda<0\right)$, unique solution $\left(\Lambda=\Lambda_{c}\right)$, or no solution $\left(\Lambda<\Lambda_{c}\right)$ is obtained, where $\Lambda_{c}$ is the critical value of $\Lambda$ for which the solution exists. At $\Lambda=\Lambda_{c}$, both solution branches are connected; thus a unique solution is obtained. For the assisting flow, dual solutions exist for all values of 


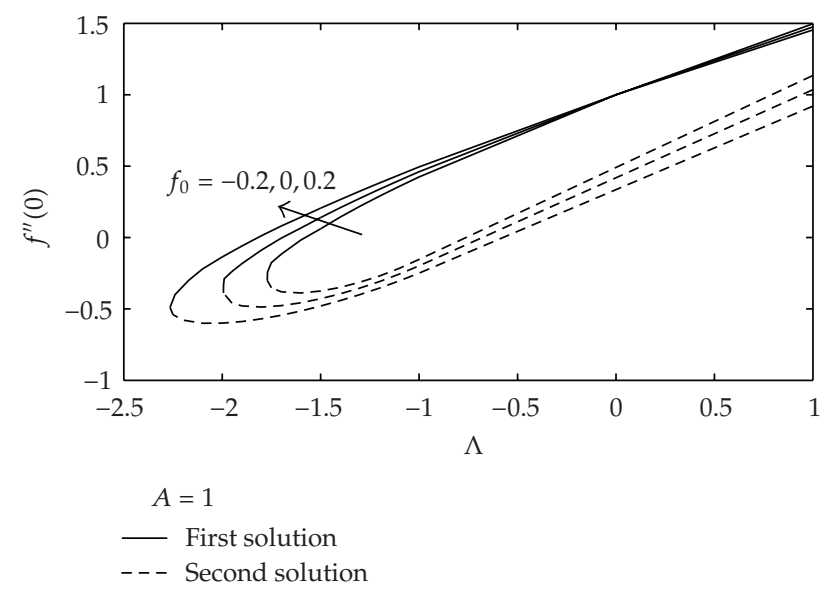

Figure 2: Variation of the skin friction function $f^{\prime \prime}(0)$ with $\Lambda$ for different values of $f_{0}$ when $A=1$.

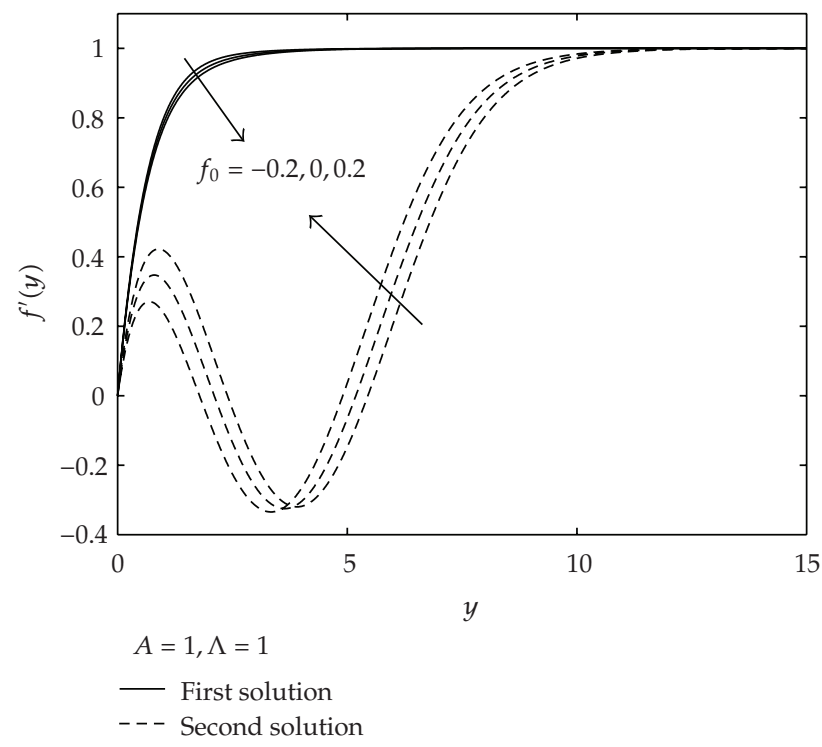

Figure 3: Velocity profiles $f^{\prime}(y)$ for different values of $f_{0}$ when $A=1$ and $\Lambda=1$ (assisting flow).

$\Lambda$ considered in this study, whereas for the opposing flow, the solutions exist up to certain values of $\Lambda$, that is, $\Lambda_{c}$. Beyond these critical values, the boundary layer separates from the surface; thus no solution is obtained using the boundary layer approximations. Moreover, from Figures 2 and 5, we found that the values of $|\Lambda|$ for which the solution exists increase as $f_{0}$ increases. Hence, suction delays the boundary layer separation. Numerical results for the local Nusselt number as presented in Figure 5 show that $-\theta^{\prime}(0)$ approaches $+\infty$ as $\Lambda \rightarrow 0^{+}$, and $-\infty$ as $\Lambda \rightarrow 0^{-}$. In Figure 2, following the first solution for a particular value of $f_{0}$, one may expect that the solution suddenly disappears at the separation point $\Lambda=\Lambda_{c}$, but this is not the case. The solution makes a $U$-turn at this point and form the second solution. It is worth mentioning that the separation occurs here at the point where $f^{\prime \prime}(0) \neq 0$. Wilks and Bramley [42] stopped the second solutions when the wall heat transfer 


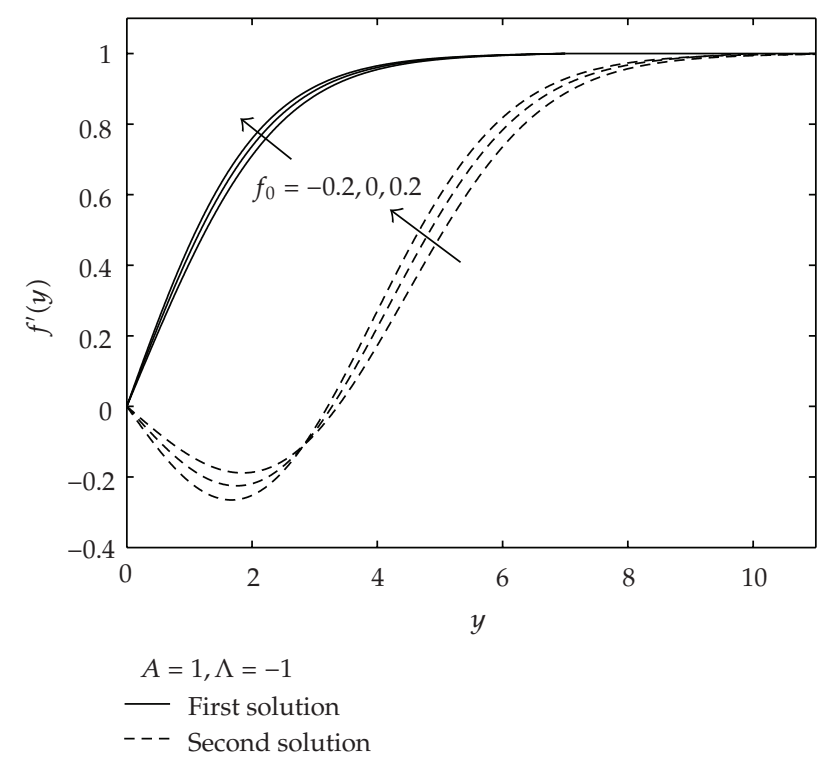

Figure 4: Velocity profiles $f^{\prime}(y)$ for different values of $f_{0}$ when $A=1$ and $\Lambda=-1$ (opposing flow).

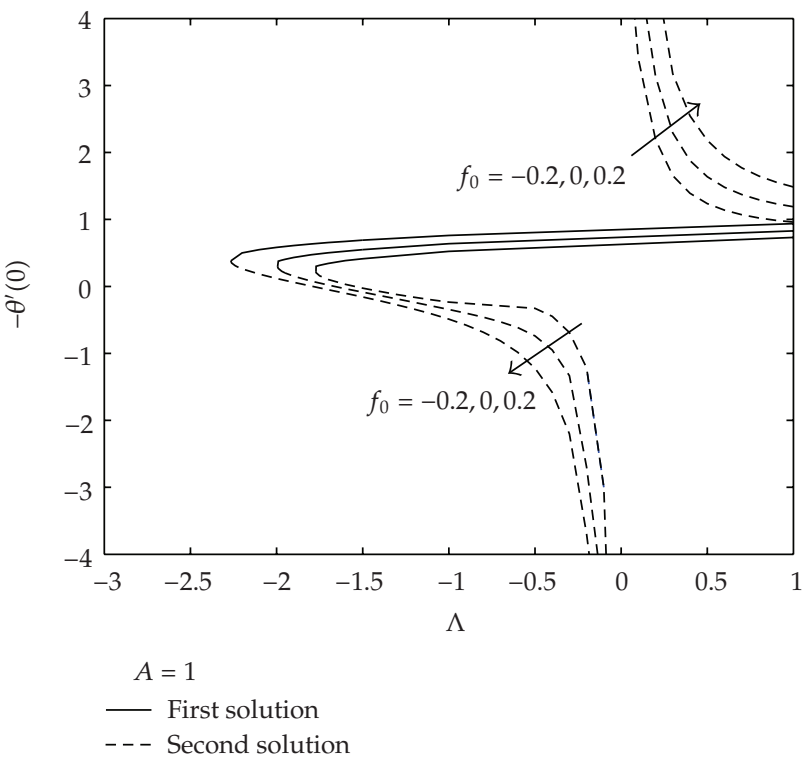

Figure 5: Variation of the Nusselt number $-\theta^{\prime}(0)$ with $\Lambda$ for different values of $f_{0}$ when $A=1$.

goes to zero. Although physically it is a realistic thing to do, it was shown by Mahmood and Merkin [43] that the second solutions could be continued further to the point where the buoyancy parameter goes to zero and terminated at this point. It seems that Ridha [44] was the first to show the existence of dual (nonuniqueness) solutions for both aiding and opposing flow situations. In the present paper, we show that the second solutions exist in the opposing flow regime $(\Lambda<0)$ and they continue into the assisting flow regime $(\Lambda>0)$, 


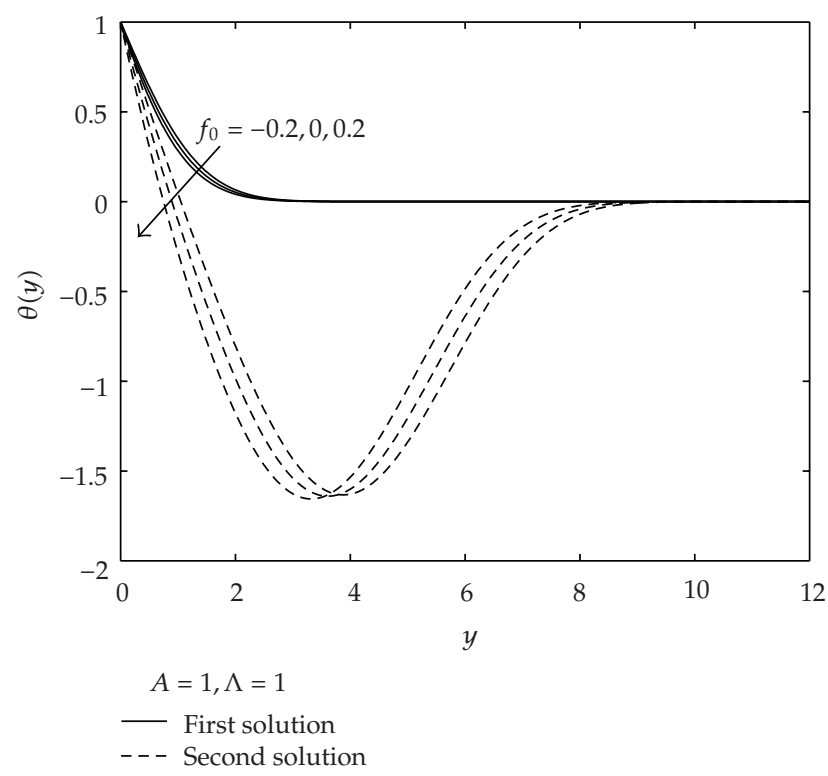

Figure 6: Temperature profiles $\theta(y)$ for different values of $f_{0}$ when $A=1$ and $\Lambda=1$ (assisting flow).

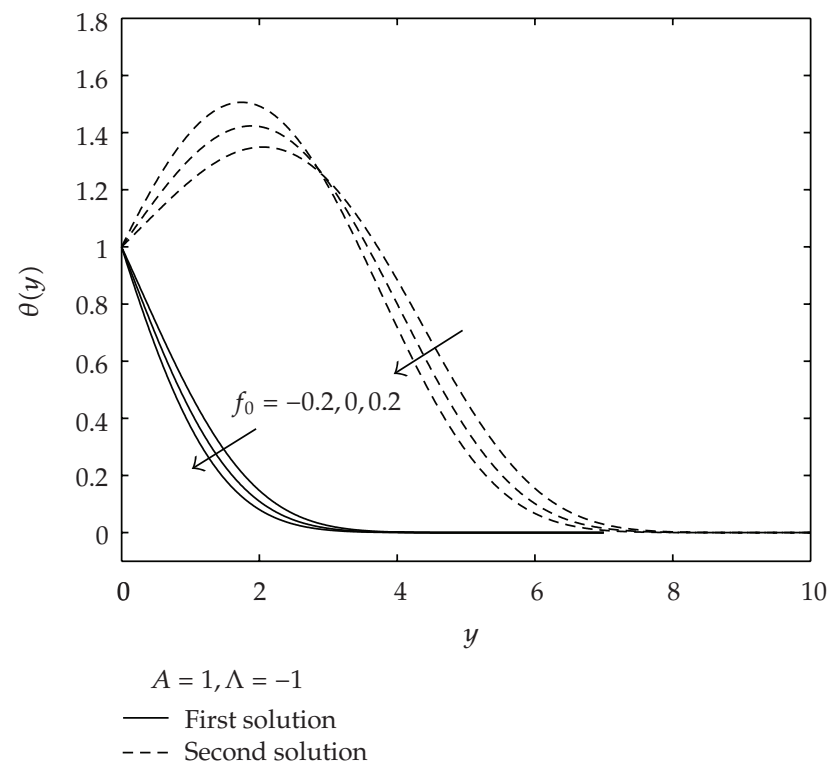

Figure 7: Temperature profiles $\theta(y)$ for different values of $f_{0}$ when $A=1$ and $\Lambda=-1$ (assisting flow).

which is in agreement with Ridha [44]. However, as discussed by Ridha [44] and Ishak et al. [30], the second solutions have no physical sense. Although such solutions are deprived of physical significance, they are nevertheless of mathematical interest as well as of physical terms so far as the differential equations are concerned. Besides, similar equations may arise in other situations where the corresponding solutions could have more realistic meaning (Ridha [45]). 


\section{Conclusions}

We have theoretically studied the existence of dual similarity solutions in mixed convection boundary layer flow over a permeable vertical plate embedded in an anisotropic porous medium with suction and injection. The governing boundary layer equations have been solved numerically for both assisting and opposing flow regimes using the Keller-box method. Discussions for the effects of suction or injection parameter $f_{0}$ and the modified mixed convection parameter $\Lambda$ on the skin friction coefficient $f^{\prime \prime}(0)$ and the Nusselt number $-\theta^{\prime}(0)$ for $A=1$ have been done. It is found that dual solutions exist for both assisting and opposing flows. It is shown that introducing suction effect increases the range of $\Lambda$ for which the solution exists and in consequence delays the boundary layer separation, while it is found that injection acts in the opposite manner.

\section{References}

[1] D. B. Ingham and I. Pop, Transport Phenomena in Porous Media, Elsevier, Oxford, UK, 2005.

[2] K. Vafai, Handbook of Porous Media, Taylor \& Francis, Boca Raton, Fla, USA, 2nd edition, 2005.

[3] D. A. Nield and A. Bejan, Convection in Porous Media, Springer, New York, NY, USA, 3rd edition, 2006.

[4] P. Vadasz, Emerging Topics in Heat and Mass Transfer in Porous Media, Springer, New York, NY, USA, 2008.

[5] E. Magyari, D. A. S. Rees, and B. Keller, "Effect of viscous dissipation on the flow in fluid saturated porous media," in Handbook of Porous Media II, chapter 9, pp. 373-406, Taylor \& Francis, Boca Raton, Fla, USA, 2005.

[6] W. J. Minkowycz and P. Cheng, "Free convection about a vertical cylinder embedded in a porous medium," International Journal of Heat and Mass Transfer, vol. 19, no. 7, pp. 805-813, 1976.

[7] P. Cheng and W. J. Minkowycz, "Free convection about a vertical flat plate embedded in a porous medium with application to heat transfer from a dike," Journal of Geophysical Research, vol. 82, no. 14, pp. 2040-2044, 1977.

[8] H. M. Badr and I. Pop, "Combined convection from an isothermal horizontal rod buried in a porous medium," International Journal of Heat and Mass Transfer, vol. 31, no. 12, pp. 2527-2541, 1988.

[9] M. Kaviany, "boundary-layer treatment of forced convection heat transfer from a semi-infinite flat plate embedded in porous media," Journal of Heat Transfer, vol. 109, no. 2, pp. 345-349, 1987.

[10] J.-Y. Jang and C.-T. Shiang, “The mixed convection plume along a vertical adiabatic surface embedded in a non-Darcian porous medium," International Journal of Heat and Mass Transfer, vol. 40, no. 7, pp. 1693-1699, 1997.

[11] C. T. Hsu and P. Cheng, "The Brinkman model for natural convection about a semi-infinite vertical flat plate in a porous medium," International Journal of Heat and Mass Transfer, vol. 28, no. 3, pp. 683-697, 1985.

[12] D. A. S. Rees and K. Vafai, "Darcy-Brinkman free convection from a heated horizontal surface," Numerical Heat Transfer, vol. 35, no. 2, pp. 191-204, 1999.

[13] R. Nazar, N. Amin, D. Filip, and I. Pop, "The Brinkman model for the mixed convection boundary layer flow past a horizontal circular cylinder in a porous medium," International Journal of Heat and Mass Transfer, vol. 46, no. 17, pp. 3167-3178, 2003.

[14] R. Nazar, N. Amin, and I. Pop, "Unsteady mixed convection boundary layer flow near the stagnation point on a vertical surface in a porous medium," International Journal of Heat and Mass Transfer, vol. 47, no. 12-13, pp. 2681-2688, 2004.

[15] A. Ishak, R. Nazar, and I. Pop, "Steady and unsteady boundary layers due to a stretching vertical sheet in a porous medium using Darcy-Brinkman equation mode," International Journal of Applied Mechanics and Engineering, vol. 11, pp. 623-637, 2006.

[16] S. D. Harris, D. B. Ingham, and I. Pop, "Mixed convection boundary-layer flow near the stagnation point on a vertical surface in a porous medium: brinkman model with slip," Transport in Porous Media, vol. 77, no. 2, pp. 267-285, 2009. 
[17] P. Cheng, "The influence of lateral mass flux on free convection boundary layers in a saturated porous medium," International Journal of Heat and Mass Transfer, vol. 20, no. 3, pp. 201-206, 1977.

[18] J. H. Merkin, "Free convection boundary layers in a saturated porous medium with lateral mass flux," International Journal of Heat and Mass Transfer, vol. 21, no. 12, pp. 1499-1504, 1978.

[19] W. J. Minkowycz, P. Cheng, and F. Moalem, "The effect of surface mass transfer on buoyancy-induced darcian flow adjacent to a horizontal heated surface," International Communications in Heat and Mass Transfer, vol. 12, no. 1, pp. 55-65, 1985.

[20] F. C. Lai and F. A. Kulacki, "The influence of surface mass flux on mixed convection over horizontal plates in saturated porous media," International Journal of Heat and Mass Transfer, vol. 33, no. 3, pp. 576-579, 1990.

[21] F. C. Lai and F. A. Kulacki, "Influence of lateral mass flux on mixed convection over inclined surfaces in saturated porous media," International Journal of Heat and Mass Transfer, vol. 112, no. 2, pp. 515-518, 1990.

[22] E. M. A. Elbashbeshy and M. A. A. Bazid, "The mixed convection along a vertical plate with variable surface heat flux embedded in porous medium," Applied Mathematics and Computation, vol. 125, no. 2-3, pp. 317-324, 2002.

[23] E. M. A. Elbashbeshy, "The mixed convection along a vertical plate embedded in non-Darcian porous medium with suction and injection," Applied Mathematics and Computation, vol. 136, no. 1, pp. 139-149, 2003.

[24] E. M. A. Elbashbeshy and M. A. A. Bazid, "Heat transfer over a continuously moving plate embedded in non-Darcian porous medium," International Journal of Heat and Mass Transfer, vol. 43, no. 17, pp. 3087-3092, 2000.

[25] E. M. A. Elbashbeshy, "Laminar mixed convection over horizontal flat plate embedded in a nonDarcian porous medium with suction and injection," Applied Mathematics and Computation, vol. 121, no. 2-3, pp. 123-128, 2001.

[26] M. A. Chaudhary and J. H. Merkin, "The effects of blowing and suction on free convection boundary layers on vertical surfaces with prescribed heat flux," Journal of Engineering Mathematics, vol. 27, no. 3, pp. 265-292, 1993.

[27] M. Massoudi, "Local non-similarity solutions for the flow of a non-Newtonian fluid over a wedge," International Journal of Non-Linear Mechanics, vol. 36, no. 6, pp. 961-976, 2001.

[28] P. D. Weidman, D. G. Kubitschek, and A. M. J. Davis, "The effect of transpiration on self-similar boundary layer flow over moving surfaces," International Journal of Engineering Science, vol. 44, no. 11-12, pp. 730-737, 2006.

[29] P. D. Weidman, A. M. J. Davis, and D. G. Kubitschek, “Crocco variable formulation for uniform shear flow over a stretching surface with transpiration: multiple solutions and stability," Journal of Applied Mathematics and Physics, vol. 59, no. 2, pp. 313-332, 2008.

[30] A. Ishak, R. Nazar, N. M. Arifin, and I. Pop, "Dual solutions in mixed convection flow near a stagnation point on a vertical porous plate," International Journal of Thermal Sciences, vol. 47, no. 4, pp. 417-422, 2008.

[31] P. Vasseur and G. Degan, "Free convection along a vertical heated plate in a porous medium with anisotropic permeability," International Journal of Numerical Methods for Heat and Fluid Flow, vol. 8, no. 1, pp. 43-63, 1998.

[32] P. Bera and A. Khalili, "Double-diffusive natural convection in an anisotropic porous cavity with opposing buoyancy forces: multi-solutions and oscillations," International Journal of Heat and Mass Transfer, vol. 45, no. 15, pp. 3205-3222, 2002.

[33] J. H. Merkin, "Mixed convection boundary layer flow on a vertical surface in a saturated porous medium," Journal of Engineering Mathematics, vol. 14, no. 4, pp. 301-313, 1980.

[34] T. Cebeci and P. Bradshaw, Physical and Computational Aspects of Convective Heat Transfer, Springer, New York, NY, USA, 1988.

[35] H. B. Keller, "Numerical methods in boundary-layer theory," Annual Review of Fluid Mechanics, vol. 10, pp. 417-433, 1978.

[36] A. Ishak, "Mixed convection boundary layer flow over a vertical cylinder with prescribed surface heat flux," Journal of Physics. A, vol. 42, no. 19, Article ID 195501, 2009.

[37] A. Ishak, "Radiation effects on the flow and heat transfer over a moving plate in a parallel stream," Chinese Physics Letters, vol. 26, no. 3, Article ID 034701, 2009. 
[38] A. Ishak, R. Nazar, and I. Pop, "Heat transfer over an unsteady stretching permeable surface with prescribed wall temperature," Nonlinear Analysis, vol. 10, no. 5, pp. 2909-2913, 2009.

[39] A. Ishak, R. Nazar, and I. Pop, "MHD convective flow adjacent to a vertical surface with prescribed wall heat flux," International Communications in Heat and Mass Transfer, vol. 36, no. 6, pp. 554-557, 2009.

[40] A. Ishak, R. Nazar, and I. Pop, "Boundary layer flow and heat transfer over an unsteady stretching vertical surface," Meccanica, vol. 44, no. 4, pp. 369-375, 2009.

[41] A. Ishak, R. Nazar, N. Bachok, and I. Pop, "MHD mixed convection flow near the stagnation-point on a vertical permeable surface," Physica A, vol. 389, no. 1, pp. 40-46, 2010.

[42] G. Wilks and J. S. Bramley, "Dual solutions in mixed convection," Proceedings of the Royal Society of Edinburgh, vol. 87, no. 3-4, pp. 349-358, 1981.

[43] T. Mahmood and J. H. Merkin, "Similarity solutions in axisymmetric mixed-convection boundarylayer flow," Journal of Engineering Mathematics, vol. 22, no. 1, pp. 73-92, 1988.

[44] A. Ridha, "Aiding flows non-unique similarity solutions of mixed-convection boundary-layer equations," Journal of Applied Mathematics and Physics, vol. 47, no. 3, pp. 341-352, 1996.

[45] A. Ridha, "Three-dimensional mixed convection laminar boundary-layer near a plane of symmetry," International Journal of Engineering Science, vol. 34, no. 6, pp. 659-675, 1996. 


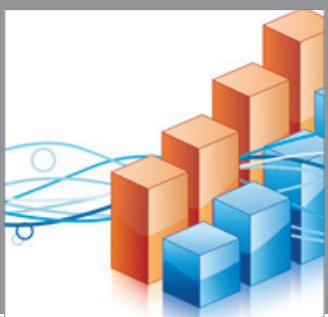

Advances in

Operations Research

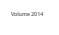

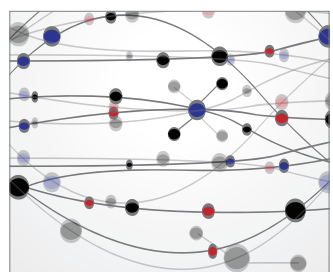

\section{The Scientific} World Journal
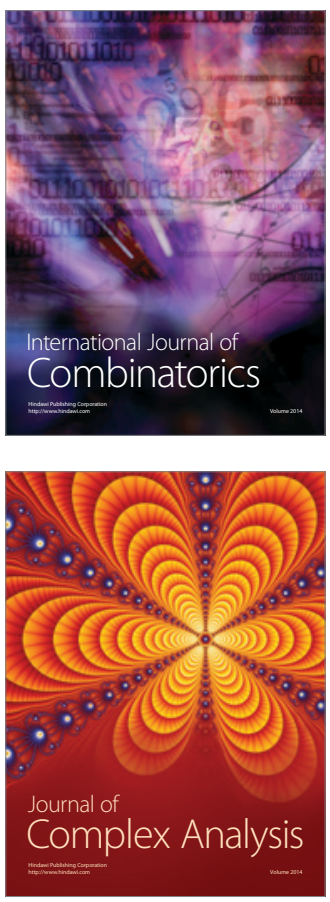

International Journal of

Mathematics and

Mathematical

Sciences
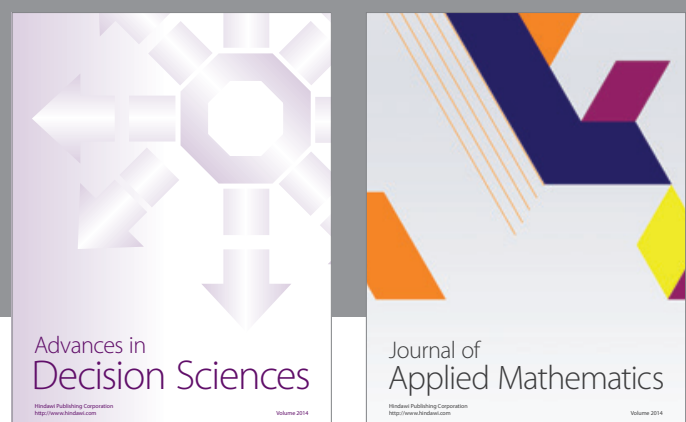

Journal of

Applied Mathematics
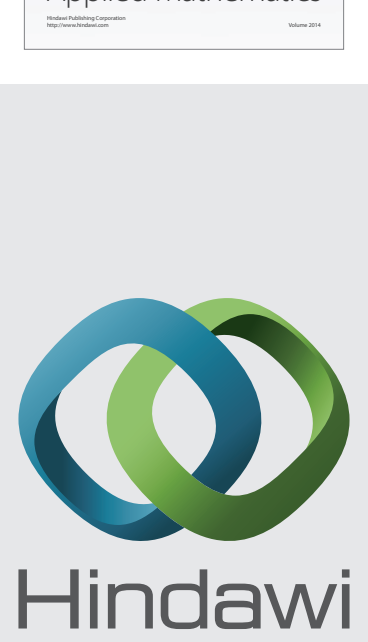

Submit your manuscripts at http://www.hindawi.com
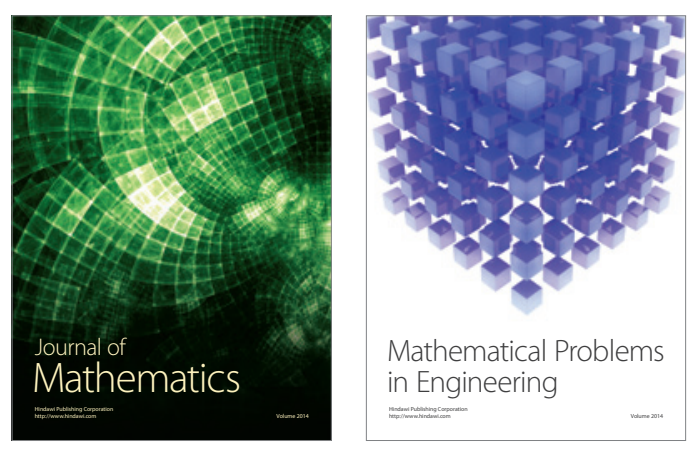

Mathematical Problems in Engineering
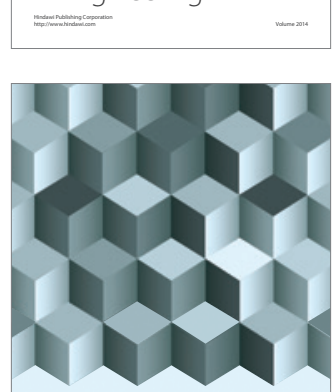

Journal of

Function Spaces
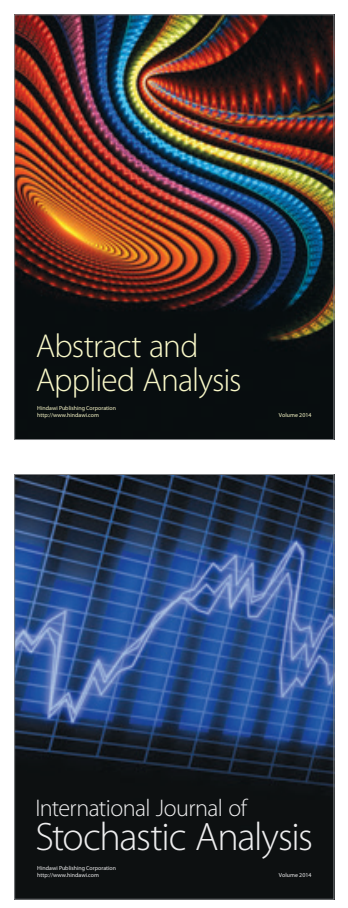

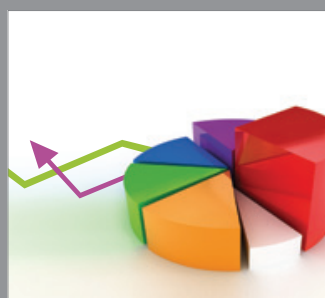

ournal of

Probability and Statistics

Promensencen
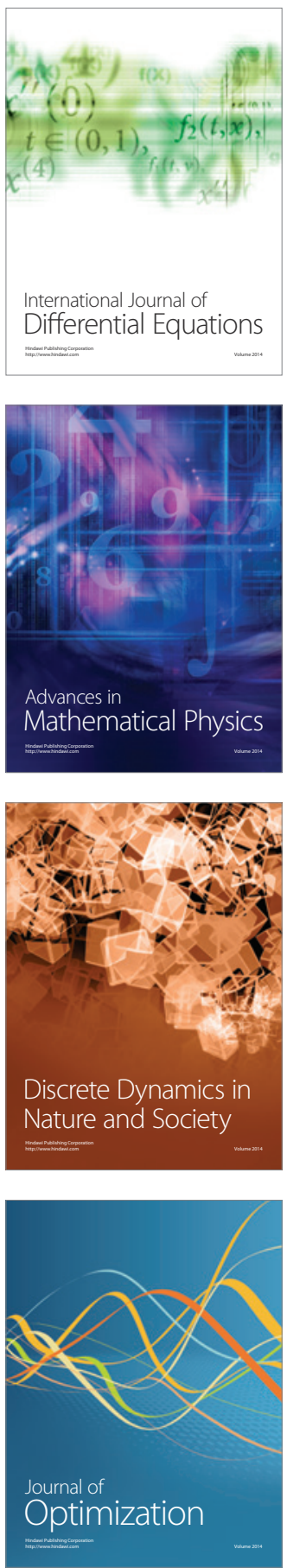